\title{
Construction of concrete supplier evaluation criteria in building industry
}

\author{
Wei Wei ${ }^{1, a}$ and Chun-Ming Yang ${ }^{2, b, *}$
}

${ }^{1}$ College of Civil Engineering and Architecture, No. 12, Jiangan Rd., Guilin 541004, China

Business School, Guilin University of Technology, No. 12, Jiangan Rd., Guilin 541004, China

a425063471@qq.com, b, ${ }^{*}$ vicyang0706@gmail.com (Corresponding author)

Keywords: Concrete; supplier evaluation; TOPSIS; building industry.

Abstract. Concrete supplier evaluation and selection in the building industry is one of the most critical processes for achieving a successful supply chain. In the past, technique for order-preference by similarity-to-ideal solution (TOPSIS) method has been extensively applied to the supplier evaluation and selection problem. In this study, six evaluation criteria (quality, price, technology, reliability, service and finance) are presented for selecting best concrete supplier in the building industry. Then, the TOPSIS is used as a powerful tool to select a suitable option. An illustrative example is offered based on a real case study to verify the feasibility and effectiveness of the proposed method.

\section{Introduction}

Concrete is the most widely used building material in the world. It plays an important role in fields of construction engineering, highway engineering, bridge and tunnel engineering, irrigation project and construction of special structure. In recent years, since the China's real estate industry has a thriving development, which relies on the construction of residents' real estate and the national projects, the market's demand for concrete has increased quickly. According to National Bureau of statistics of China [1] indicated that, in the 2016, the gross output value of construction is 193,556.78 (unit: $¥ 100$ million) and number of construction enterprises is 83,017 . Table 1 shows the some main indicators on construction enterprises situation in China in the years 2014-2016. The mode of decentralized purchasing which has been commonly used in traditional construction projects; however, it is not able to meet the needs of the multiple items project nowadays, especially for the premixed concrete of construction projects. Therefore, when the supply chain of construction enterprises forms an efficient procurement and management mode, it will create a great impact on the conduct of construction engineering of multi-project. In order to make projects smoothly going, a high-quality product with a low price in a timely manner is necessary. Hence, an important issue for the construction enterprises is to select a suitable concrete supplier.

In fact, the selection of multi-project concrete suppliers is a multiple-criteria decision-making (MCDM) problem. For this, TOPSIS method is a best solution for solving MCDM problem [2]. The TOPSIS method avoids making decisions subjectively from human's experience, and is simple, observable and operable [3]. Obviously, the TOPSIS can not only help the decision maker to choose the best supplier from the alternative concrete suppliers, but also can provide the other relevant industry a reference for supplier selection, so that to improve the product quality and competitiveness [4]. This study first presents six criteria that must be considered in the selection process of the concrete supplier, both quantitative and qualitative. Then, the TOPSIS method is adopted as the research method to evaluate and select the concrete suppliers of a company in the building industry. An illustrative example is given clarify the effectiveness of the proposed method.

Table 1 The construction enterprises situation in China in the years 2014-2016

\begin{tabular}{lccc}
\hline & 2014 & 2015 & 2016 \\
\hline Gross output value of construction (unit: ¥100 million) & $176,713.40$ & $180,757.47$ & $193,556.78$ \\
Number of construction enterprises & 81,141 & 80,911 & 83,017 \\
\hline
\end{tabular}




\section{Concrete supplier evaluation criteria}

On the basis of introducing the past studies of supplier selection into building industry, six criteria, quality, price, technology, reliability, service and finance, for the evaluation and selection of concrete supplier are selected in this study. Moreover, according to the nature of each criterion, it is divided into benefit type or cost type, as shown in Table 2. The detailed contents of all the six evaluation criteria are presented below.

Table 2 Six evaluation criteria for concrete supplier selection

\begin{tabular}{lcc}
\hline Criterion & Type & Proposed by \\
\hline Quality & Benefit & Auhan [5] \\
Price & Cost & Arabsheybani et al. [6] \\
Technology & Benefit & Manello and Calabrese [7] \\
Reliability & Benefit & Chen and Chao [8] \\
Service & Benefit & Lin and Purchase [9] \\
Finance & Benefit & Rezaei et al. [10] \\
\hline
\end{tabular}

\section{TOPSIS}

Among many famous MCDM methods, TOPSIS is the best way to solve MCDM problems [11]. The TOPSIS method consists of the following six steps:

Step 1: Construct a decision matrix $D$ based on the outcome for each alternative using 1-10 scores (note: when the evaluation criterion is a benefit criterion, a higher score means higher importance; on the other hand, when the evaluation criterion is a cost criterion, a lower score means higher importance) by all decision makers as follows:

$$
\begin{aligned}
& \begin{array}{llll}
C_{1} & C_{2} & \mathrm{~L} & C_{n}
\end{array} \\
& D=\frac{S_{1}}{S_{2}} \underset{\mathrm{M}}{S_{m}}\left[\begin{array}{cccc}
x_{11} & x_{12} & \mathrm{~L} & x_{1 n} \\
x_{21} & x_{22} & \mathrm{~L} & x_{2 n} \\
\mathrm{M} & \mathrm{M} & \mathrm{O} & \mathrm{M} \\
x_{m 1} & x_{m 2} & \mathrm{~L} & x_{m n}
\end{array}\right]
\end{aligned}
$$

where $S_{i}$ denotes the alternatives $i=1, \ldots, m ; C_{j}$ represents the criteria $j=1, \ldots, n ; x_{i j}$ represents $j$ th criterion related to $i$ th alternative; and $x_{i j}$ is the obtained value indicating the performance rating of each alternative $S_{i}$ with respect to each criterion $C_{j}$.

Step 2: Calculate the normalized decision matrix $R$ as follows:

$$
\begin{aligned}
& \begin{array}{llll}
C_{1} & C_{2} & \mathrm{~L} & C_{n}
\end{array} \\
& R=\begin{array}{c}
S_{2} \\
\mathrm{M} \\
S_{m}
\end{array}\left[\begin{array}{cccc}
e_{11} & e_{12} & \mathrm{~L} & e_{1 n} \\
e_{21} & e_{22} & \mathrm{~L} & e_{2 n} \\
\mathrm{M} & \mathrm{M} & \mathrm{O} & \mathrm{M} \\
e_{m 1} & e_{m 2} & \mathrm{~L} & e_{m n}
\end{array}\right]
\end{aligned}
$$

where $e_{i j}=x_{i j} / \sqrt{\sum_{i=1}^{m} x_{i j}^{2}}, j=1,2, \mathrm{~K}, n$ denotes the normalized value.

Step 3: Compute the weighted normalized decision matrix $W$ as follows:

$$
W=\begin{gathered}
C_{1} \\
S_{2} \\
\mathrm{M} \\
S_{m}
\end{gathered}\left[\begin{array}{cccc}
v_{11} & v_{12} & \mathrm{~L} & v_{1 n} \\
v_{21} & v_{22} & \mathrm{~L} & v_{2 n} \\
\mathrm{M} & \mathrm{M} & \mathrm{O} & \mathrm{M} \\
v_{m 1} & v_{m 2} & \mathrm{~L} & v_{m n}
\end{array}\right]
$$


where the weighted normalized value $v_{i j}=w_{j} \times e_{i j}, i=1,2, \mathrm{~K}, m ; j=1,2, \mathrm{~K}, n$ and $w_{j}$ represents the weight of the $j$ th criterion which is given by expert experience using $0-1$ scores.

Step 4: Determine the ideal solution $I^{+}$and nadir ideal solution $I^{-}$. The ideal values set and the nadir ideal values set are determined as follows:

$$
I^{+}=\left(v_{1}^{+}, \ldots, v_{n}^{+}\right)=\left\{\left(\max v_{i j} \mid j \in J\right),\left(\min v_{i j} \mid j \in J^{\prime}\right)\right\}, i=1,2, \mathrm{~K}, m
$$

and

$$
I^{-}=\left(v_{1}^{-}, \ldots, v_{n}^{-}\right)=\left\{\left(\min v_{i j} \mid j \in J\right),\left(\max v_{i j} \mid j \in J^{\prime}\right)\right\}, i=1,2, \mathrm{~K}, m
$$

where $J$ and $J^{\prime}$ are the sets of benefit criteria and cost criteria, respectively.

Step 5: Measure the distance for each alternative from ideal and nadir ideal solutions as follows:

$$
F^{+}=\left\{\sum_{j=1}^{n}\left(v_{i j}-v_{j}^{+}\right)^{2}\right\}^{0.5}, i=1,2, \mathrm{~K}, m
$$

and

$$
F^{-}=\left\{\sum_{j=1}^{n}\left(v_{i j}-v_{j}^{-}\right)^{2}\right\}^{0.5}, i=1,2, \mathrm{~K}, m
$$

Step 6: Compute the relative closeness $T$ to the ideal solution as follows:

$$
T=\frac{F_{i}^{-}}{F_{i}^{+}+F_{i}^{-}}, \quad i=1, \ldots, m
$$

The higher the value of relative closeness, the better the performance of the alternative.

\section{Illustrative example: concrete supplier selection of a building company}

An illustrative example for concrete supplier selection of a building company $\mathrm{G}$ is presented to illustrate the analysis of the proposed method. Five concrete suppliers and six evaluation criteria (Table 2) are selected for the illustrative example, and the six concrete suppliers' performance values at the selected criteria are determined by three decision makers in Tables 3 (note: all evaluated scores given by the three decision makers are computed using the arithmetic mean). Then, the TOPSIS method in Section 3 is adopted for determining which concrete supplier had the best performance involved the following six steps:

Step 1: A decision matrix is constructed in Table 3.

Step 2: A normalized decision matrix is constructed in Table 3.

Step 3: A weighted normalized decision matrix is constructed and the weights of the six criteria are determined by two building experts using 0-1 scores in Table 4.

Step 4: The ideal values set and the nadir ideal values set are $(0.20,0.11,0.15,0.13,0.19,0.16)$ and $(0.14,0.15,0.07,0.07,0.09,0.12)$, respectively.

Step 5: The results of the distance for each supplier from ideal solution and nadir ideal solutions are shown in Table 5.

Step 6: The results of the relative closeness $T$ to the ideal solution are shown in Table 5. Thus, the best concrete supplier was determined to be the Supplier 1.

Table 3 Original scores and normalized scores of five concrete suppliers

\begin{tabular}{cccccccccccccc}
\hline \multirow{2}{*}{ Criterion } & \multicolumn{2}{c}{ Quality } & \multicolumn{2}{c}{ Price } & \multicolumn{3}{c}{ Technology } & \multicolumn{2}{c}{ Reliability } & \multicolumn{2}{c}{ Service } & \multicolumn{2}{c}{ Finance } \\
\cline { 2 - 15 } Supplier & $\mathrm{O}$ & $\mathrm{N}$ & $\mathrm{O}$ & $\mathrm{N}$ & $\mathrm{O}$ & $\mathrm{N}$ & $\mathrm{O}$ & $\mathrm{N}$ & $\mathrm{O}$ & $\mathrm{N}$ & $\mathrm{O}$ & $\mathrm{N}$ \\
\hline Supplier 1 & 6.33 & 0.24 & 6.33 & 0.20 & 7.00 & 0.23 & 5.00 & 0.18 & 8.67 & 0.27 & 6.67 & 0.21 \\
Supplier 2 & 6.00 & 0.23 & 5.67 & 0.18 & 3.67 & 0.12 & 4.67 & 0.17 & 6.33 & 0.20 & 5.67 & 0.18 \\
Supplier 3 & 5.00 & 0.19 & 5.33 & 0.17 & 5.67 & 0.18 & 4.00 & 0.14 & 7.33 & 0.23 & 6.67 & 0.21 \\
Supplier 4 & 5.00 & 0.19 & 7.00 & 0.22 & 8.00 & 0.26 & 6.67 & 0.24 & 4.33 & 0.13 & 5.67 & 0.18 \\
Supplier 5 & 4.33 & 0.16 & 7.33 & 0.23 & 6.67 & 0.22 & 7.33 & 0.27 & 5.67 & 0.18 & 7.33 & 0.23 \\
Note: O: original; N: normalized & & & & & & & & & \\
\hline
\end{tabular}


Table 4 Weighted normalized scores of five concrete suppliers and weights of six criteria

\begin{tabular}{|c|c|c|c|c|c|c|}
\hline \multirow[b]{2}{*}{ Weight } & Quality & Price & Technology & Reliability & Service & Finance \\
\hline & 0.85 & 0.65 & 0.60 & 0.50 & 0.70 & 0.60 \\
\hline Supplier 1 & 0.20 & 0.13 & 0.14 & 0.09 & 0.19 & 0.15 \\
\hline Supplier 2 & 0.19 & 0.12 & 0.07 & 0.08 & 0.14 & 0.12 \\
\hline Supplier 3 & 0.16 & 0.11 & 0.11 & 0.07 & 0.16 & 0.15 \\
\hline Supplier 4 & 0.16 & 0.14 & 0.15 & 0.12 & 0.09 & 0.12 \\
\hline Supplier 5 & 0.14 & 0.15 & 0.13 & 0.13 & 0.12 & 0.16 \\
\hline \multicolumn{7}{|c|}{ Table 5 Results of five concrete suppliers } \\
\hline Supplier & \multicolumn{2}{|c|}{$F^{+}$} & $F^{-}$ & $T$ & \multicolumn{2}{|r|}{ Rank } \\
\hline Supplier 1 & \multicolumn{2}{|c|}{0.05} & 0.14 & 0.74 & \multicolumn{2}{|r|}{1} \\
\hline Supplier 2 & \multicolumn{2}{|c|}{0.11} & 0.08 & 0.41 & \multicolumn{2}{|r|}{5} \\
\hline Supplier 3 & \multicolumn{2}{|c|}{0.09} & 0.09 & 0.52 & \multicolumn{2}{|r|}{2} \\
\hline Supplier 4 & \multicolumn{2}{|c|}{0.12} & 0.10 & 0.47 & \multicolumn{2}{|r|}{4} \\
\hline Supplier 5 & \multicolumn{2}{|c|}{0.10} & 0.10 & 0.50 & \multicolumn{2}{|r|}{3} \\
\hline
\end{tabular}

\section{Conclusions}

In practice, managers in the building industry often lack objective decision making procedures and clearly defined evaluation criteria for selecting best concrete supplier. Such problems can be solved by the systematic method proposed in this study. For this, TOPSIS method is applied to evaluate five concrete suppliers with respect to six evaluation criteria (quality, price, technology, reliability, service and finance) for a building company G. The analysis results in Table 6 showed the best concrete supplier was Supplier 1. Therefore, the proposed method will be a powerful tool for evaluation and selection of the concrete supplier in the building industry.

\section{Acknowledgements}

This work is financially supported by National Natural Science Foundation of China under Grant No. 71762008 and 71762009 and Guilin University of Technology under Grant No. GUTQDJJ6616075

\section{References}

[1] Information on http://data.stats.gov.cn/english/easyquery.htm?cn=C01

[2] C.L. Hwang and K. Yoon, Multiple Attribute Decision Making: Methods and Applications, edited by Springer-Verlag, NY (1981).

[3] P. Sirisawat, and T. Kiatcharoenpol: Comput. Ind. Eng. Vol. 117 (2018), pp. 303-318.

[4] A. Bilbao-Terol, M. Arenas-Parra, V. Cañal-Fernández and J. Antomil-Ibias: Omega-Int. J. Manage. S. Vol. 49 (2014), pp. 1-17.

[5] M.B. Auhan: Int. J. Managing Value Supply Chains Vol. 4 (2013), pp. 11-23.

[6] A. Arabsheybani, M.M. Paydar and A.S. Safaei: J. Clean. Prod. Vol. 190 (2018), pp. 577-591.

[7] A. Manello, and G. Calabrese: J. Purch. Supply Manage. (2018), in press.

[8] Y.H. Chen and R.J. Chao: Expert Syst. Appl. Vol. 39 (2012), pp. 3233-3240.

[9] X. Lin and S. Purchase: Investigating supplier selection using repertory grid technique. Service Operations and Logistics, and Informatics, (2006), pp. 432-435.

[10] J. Rezaei, J. Wang, and L. Tavasszy: Expert Syst. Appl. Vol. 42 (2015), pp. 9152-9164.

[11] L.Y. Ouyang, K.S. Chen, C.M. Yang and C.H. Hsu: Int. J. Prod. Res. Vol. 52 (2014), pp. 3110-3124. 